\title{
Confronting consolidation issues: Is this the right move for you?
}

\section{It's important to understand the rules that govern M\&A.}

\author{
Michael Lytton
}

There has been growing dissatisfaction on the part of investors with the various business models that have characterized the biotechnology industry over the past decade. They claim the biotechnology industry is more a love affair with science than a real business. Moreover, unabated venture capital funding worldwide has resulted in what some say are too many biotechnology companies competing for too few public-equity dollars. The sobering fact is that of the 298 companies that raised money during the high-flying 1995-1996 biotechnology funding window, at least 94 now have less than $\$ 20$ million in cash remaining. Depending on the amount the company burns each year, this is approximately one to two years' worth of funds.

This financial crunch comes at a time when the opportunities for biotechnology look better than ever. Progress in the Human Genome Project and other initiatives has led to an explosion of new biological and chemical information highly relevant to the discovery of new drugs. The implosion of the pharmaceutical industry through mergers and acquisitions leaves fewer internal $\mathrm{R} \& \mathrm{D}$ dollars devoted to analyzing this information, suggesting it is up to biotechnology companies to take the lead. The public's seemingly insatiable demand for new drugs to treat the maladies of an aging population continues to drive the healthcare market.

What can be done to resolve the inherent conflict between the serious funding shortage and the rapid expansion of technology and product opportunities? Increasingly, the financial and pharmaceutical industries have been arguing for an increase in M\&A in the biotechnology sector. There are a number of reasons to think this will address many of the biotechnology industry's current financial woes. But it is unlikely this will be accomplished through traditional M\&A deal structures. What this suggests for companies investigating this alternative is that they will need to be as innovative in their M\&A activities as they are in developing new technologies.

Michael Lytton is partner and chairman of the technology group at Palmer \& Dodge, One Beacon Street, Boston, MA 02108-3190 (mlytton@palmerdodge.com).

\section{In the face of tradition}

While the power of the M\&A logic is slowly catching on in biotechnology, there are significant hurdles to be overcome. This is because many of the traditional arguments for industry consolidation simply do not apply to the biotechnology industry. For example, the rationale behind the recent pharmaceutical company mergers is their achievement of economies of scale-increasing the size of the organization increases revenues and market power while permitting elimination of inefficient resource usage and cost-cutting.

\section{While the power of the M\&A} logic is slowly catching on in biotechnology, there are significant hurdles to overcome.

But this principle does not translate easily for biotechnology companies. For example, biotechnology manufacturing facilities tend to be specially designed so that they are useful only for a single product or possibly a few related products. In a merged organization, their usefulness is not likely to increase through higher throughput.

In the same way, twice as many researchers, especially if their specialties are scattered between the two companies' R\&D departments, will not necessarily be twice as productive. While the goal of having twice as many sales personnel is appealing to pharmaceutical companies, the fact that there generally are no salespeople in a biotechnology company negates that traditional M\&A rationale. Generally, biotechnology companies rely on their pharmaceutical partners to sell their products.

Hence the limited-if any-economies of scale that are produced by most biotech-tobiotech mergers makes the prospect of adding together two significant burn rates with no enhanced productivity terrifying.

Despite these hurdles, there is a trend toward increased M\&A in selected areas of the biotechnology industry. So far, this is in the domain of the so-called tool companies. Deals such as Incyte's (Palo Alto, CA) acquisitions of Hexagen and Synteni, Princetonbased Pharmacopeia's acquisition of Molecular Simulations, Millennium's (Cambridge, MA) acquisition of Chemgenics, and Arris' merger with Sequana to form Axys (S. San Francisco, CA) are all evidence of this trend. The argument for these deals is that a pharmaceutical company customer will prefer one-stop shopping for drug-discovery services. Bigger means better here because of the ease of negotiating one contract that allows the pharmaceutical company to outsource the early stages of drug discovery and realize significant added value to their internal R\&D machine. The recent $\$ 465$ million deal between Millennium and Bayer is strong evidence of the validity of this logic.

At the other end of the drug-development pipeline, consolidation activity has been on the upswing in the merging of complementary, late-stage product portfolios. Palo Alto-based Alza's acquisition of Sequus and Elan's (Dublin, Ireland) acquisition of Neurex are two examples of this trend. Perhaps the best recent example is Peptide Therapeutics' (Cambridge, UK) acquisition of OraVax, effecting the combination of complementary bacterial and viral vaccine platforms.

This trend makes sense because the mergers bring together integratable scientific skill sets to expand product and development opportunities. The other indisputable driver in these deals is the incredible bargain that an acquirer can wind up with as a result of the moribund US public markets and the accompanying depression in public stock valuations.

\section{Structuring a merger}

Given this trend, what are the key issues in structuring a merger of two biotechnology companies? The starting point is to get a sense of relative valuation. This typically involves computing a ratio of stock prices if the candidates are two public companies, particularly if these prices have remained relatively stable during the months prior to announcement of the deal.

Privately held biotechnology companies 
are notoriously hard to value, since they typically do not have earnings, and hence are not susceptible to the financial ratio analysis normally applied to valuing acquisitions of private companies in other industries. The valuations in prior venture capital financing rounds are a partial guide, however-often these are "inside" rounds that do not offer a reliable, third-party valuation of value.

Even public biotechnology company stocks are a challenge to value, since they are often thinly traded and subject to major price fluctuations. Always reluctant to use precious cash resources, most biotechnology companies want to structure acquisitions as stockfor-stock deals, which can be quite difficult to accomplish when the stock prices of both the acquirer and the target are subject to violent fluctuations.

Private companies are usually priced by reference to acquisitions of comparable companies. An investment banker can be a helpful participant in this exercise, particularly if you are the selling company and need assistance with determining an appropriate valuation.

There are accounting and tax considerations in structuring these deals. For example, if the consideration for the acquisition is stock of the acquiring company, this may allow the acquirer to treat the acquisition for accounting purposes as a "pooling-of-interest." This is an accounting treatment that allows the acquiring company to basically add together the two companies' financial statements, increasing the possibility of generating inflated earnings - at least on paper.

"Purchase" accounting, the alternative to pooling, involves amortization of the "goodwill" component of the purchase price-the premium paid over the book value of the target company's assets. This results in a significant negative charge against the earnings of the combined company. An "all stock" deal is the most desirable from a tax perspective as it should qualify as a "tax-free reorganization."

A key issue in these deals is the effect of stock price fluctuations between the time of signing a merger agreement and closing the deal. Typically, the ratio of the price of the acquirer's stock to the target company's stock at the time of public announcement of the deal-usually when the agreement is signed-is used as the basis for calculating the number of the acquiring company shares that the target company's shareholders will receive.

Since months may pass between the signing of the agreement and the closing, an additional precautionary measure is usually invoked: A fixed 10-20\% "collar" is set around the conversion ratio so that the final conversion ratio at the closing is within that range. If the conversion ratio moves outside the collar, either party may be given the option to terminate the deal or to request a renegotiation of the basic economic terms.
Of course, there are cash acquisitions as well. These deals typically contain an "earnout" as a key feature. This means a portion of the acquisition price is tied to the future performance of the business. This makes the delivery of a portion of the purchase price contingent upon certain threshold sales or profitability objectives being met. In cash deals, buyers typically escrow some of the money for a period of six months to one year to protect themselves against undisclosed liabilities or breaches of any other representations and warranties extended by the seller prior to closing.

If everything goes as planned, the normal sequence of events is to first negotiate and sign a nonbinding letter of intent. The letter of intent will contain legally binding provisions that cover confidentiality, sharing of diligence materials, and perhaps most importantly, an exclusive "no shop" provision for a period of time. This gives the buyer the reassurance that it can invest time and resources in doing its due diligence without having the target company peddled to other potential bidders. Following this period of extensive due diligence, a definitive merger agreement is negotiated and signed, followed by the preparation of materials to solicit the approval of both companies' stockholders, stockholder meetings, and the closing.

\section{Deal derailment}

What can cause a deal to be derailed? Typical reasons relate to problems uncovered during due diligence by the buyer, such as defects in the core intellectual property portfolio, undisclosed US Food and Drug Administration regulatory issues, or threatened litigation. Selling a company bears some resemblance to selling a house. It is certainly a good idea to "tidy-up" before embarking on the selling process since an undisclosed potential liability can easily cause the process to go astray.

The other major issue that causes deals to fail is, of course, conflicts in personality or culture between the two management teams. This is not unique to biotechnology. It is, perhaps, the most difficult issue in all M\&A transactions. There can only be one management team in the combined company no matter how talented the individual players.

In putting together an acquisition, it is also challenging to mesh together the different priorities of the various constituencies involved in the decision to sell. The VC board members may have a very different perspective than the management of the company. As compensation for giving up control over their portfolio company, venture capitalists look for a significant premium over the most recent valuation of their holdings. Over the lifetime of their investment, they would like to realize an annual- ized internal rate of return of at least $25 \%$. This rate of return and valuation step-up should cover the VC's sacrifice of the undiluted upside of staying an independent company.

If the acquirer pays with stock, the VCs will insist on receiving registered stock. This will enable them to liquidate their holding in the new entity if they so choose. Acquirers, who fear that the VCs will dump shares and depress the stock price, will insist on a minimum lock-up period before the VCs can sell. VCs must also balance their desire for selling off their shares in the newly merged entity against their interest in taking a board seat or otherwise being actively involved in the governance of the new entity. Insider status restricts, as a matter of law, one's ability to trade in the stock of the combined entity. This legal principle often forces VCs to decline a board seat or accept some restrictions on their shares.

As a rule of thumb, VCs also would generally like to structure a tax-free reorganization unless their investment is being liquidated at a loss, in which case they will prefer a taxable transaction. Given the many personality and cultural issues that can derail an acquisition, VC board members can play a valuable role in negotiating the acquisition. Since a VC's stake is largely economic, they can be the "voice of reason" to break an impasse in a negotiation over noneconomic issues.

\section{Conclusions}

All the elements appear to be in place for a major increase in M\&A among biotechnology companies over the coming year. Still, any hypothesis derived from traditional economic models must be taken with a grain of salt when applied to the biotechnology industry because it has long defied convention.

The laws of supply and demand do not determine biotechnology product pricing. Private and public market valuations of biotechnology companies bear no relation to discounted cash flow or other valuation techniques commonly applied in other industries. Evolving biotechnology patent laws and regulatory policies result in evershifting barriers to entry.

Given these factors, it could be hazardous to assume economic principles which have demonstrated predictive power in other industries can be applied in a straightforward manner to the biotechnology industry. However, for those companies that can envision value enhancement through consolidation with another company, developing an innovative strategy to accomplish these types of deals may be the next step in assuring investor confidence and long-term financial self sufficiency. /// 